\title{
JOURNAL OF THE AUSTRALIAN MATHEMATICAL SOCIETY
}

Submission of research papers in all areas of pure mathematics including theoretical contributions in fields such as probability, mathematical physics and mathematical statistics are invited under the condition that the paper has not been published and is not being considered for publication anywhere else. The Journal is seeking articles of more general interest and of moderate length, preferring papers with a good introduction explaining the meaning and value of results. Articles below ten pages or much above thirty pages will usually not be accepted. In view of the pressure on space, only papers highly rated by assessors can be accepted.

For information on submission of papers, and to submit a paper, see the journal's submission system: http://mc.manuscriptcentral.com/jaz.

\section{PREPARATION OF MANUSCRIPTS}

1. Papers should be double spaced and have a generous margin. Authors should keep copies of all files.

2. Files must be prepared using $\mathrm{ET}_{\mathrm{E}} \mathrm{X}$ or another variant of $\mathrm{T}_{\mathrm{E}} \mathrm{X}$, and must not contain definitions of additional commands. A JAustMS style file can be found at: https://mc.manuscriptcentral.com/jaz. In the top right corner click on 'Instructions \& Forms'. A ScholarOne Manuscripts box will open. Click on LaTex Style Files and jaustms.zip will be sent to your downloads on your computer.

3. Each manuscript should include an abstract of no more than 150 words, preferably containing no formulae, a list of keywords, a 2010 Mathematics subject classification, and a short title of no more than 40 characters.

4. For the style of references consult recent issues of the journal. The current usage is either the number referencing [1], [2], [3], or the letter referencing, such as [DS1], [DS2], [DS3] if the authors are N. Dunford and J. T. Schwartz, and the reference is to the 3 volumes of their monograph. In either style, references should be ordered alphabetically by the first author's name. Abbreviations of journal names should follow Mathematical Reviews.

5. Avoid abbreviations such as Thm., Prop., Eq., Ex., iff. In the text do not use the symbols $\forall, \exists, \Longrightarrow$ and $\Longleftrightarrow$. For more information about our stylistic requirements, see the Journal website accessible through www.austms.org.au.

6. Graphics should be prepared to professional standards, preferably using Postscript or LTEX drawing facilities. Charges may apply if the typesetters have to recreate a graphics file because the original is not suitable for printing.

Copying: This journal is registered with the Copyright Clearance Center, 222 Rosewood Drive, Danvers, MA 01923, USA. Organizations in the USA who are registered with the CCC may therefore copy material beyond the limits permitted by sections 107 and 108 of US copyright law subject to payment to CCC of the per-copy fee of $\$ 16.00$. This consent does not extend to multiple copying for promotional and commercial purposes. Code 1446-7887/2020 \$16.00.

Organizations authorized by the Copyright Licensing Agency may also copy material subject to the usual conditions. For all other use, permission should be sought from Cambridge or the American branch of Cambridge University Press.

Published by Cambridge University Press for the Australian Mathematical Publishing Association Incorporated. Printed in the United Kingdom at Bell \& Bain Ltd, Glasgow.

(C) 2020 Australian Mathematical Publishing Association Inc.

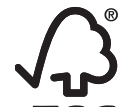

FSC
MIX

Paper from responsible sources FSC $^{\oplus}$ C007785

This journal issue has been printed on FSC-certified paper and cover board. FSC is an independent, non-governmental, not-for-profit organization established to promote the responsible management of the world's forests. Please see www.fsc.org for information. 


\section{Table of Contents}

A result of Paley and Wiener on Damek-Ricci spaces

Bhowmik, $M$.

Group algebras whose unit group is locally nilpotent

Bovdi, $V$.

On the number of subsemigroups of direct products involving the free monogenic semigroup

Clayton, A. \& Ruškuc, $\mathcal{N}$.

Generalized Jordan derivations on semiprime rings

Ferreira, B. L. M., Ferreira, R. N. \& Guzzo fr., H.

Stochastic nonlinear Schrödinger equation with almost space-time white noise Forlano, f., Oh, T. \& Wang, 1 .

Perfect triangles on the curve $C_{4}$

Ismail, $S$.

Complete Weingarten hypersurfaces satisfying an Okumura type inequality

de Lima, E. L. \&̊ de Lima, H. F.

Algebraic Cuntz-Krieger algebras

Nasr-Isfahani, $A$.

Hyperreflexivity constants of the bounded $N$-cocycle spaces of group algebras and $\mathbf{C} *$-algebras

Samei, E. \& Farsani, J. S.

A modular proof of two of Ramanujan's formulae for $1 / \pi$

Zhao, 1 . 